\title{
Jugaad: A New Innovation Mindset
}

\section{Ingo Bobel*}

Department of Economics, International University of Monaco, Monaco

The way how economists think about economic progress, growth and innovation has been pioneered by the Austrian-American economist Joseph Schumpeter (1883-1950). Academic research has led to a myriad of conceptual definitions (by linking innovation, for example, to product, process, incremental, architectural, radical, market, disruptive, organizational, complementary, social and numerous other features and characteristics) that all try to shed some light on the process of "Creative Destruction" which Schumpeter described as:

"...the opening up of new markets, foreign or domestic, and the organizational development from the craft shop to such concerns as U.S. Steel illustrate the same process of industrial mutation-if I may use that biological term-that incessantly revolutionizes the economic structure from within, incessantly destroying the old one, incessantly creating a new one. This process of Creative Destruction is the essential fact about capitalism" [1].

It was Schumpeter's [1] strong belief that a capitalist system best fulfills the necessary conditions to reach the ultimate goal of any nation (be it a developed or an emerging or under-developed country), that is, enabling its people to lead a better life and to reach a higher standard of living for everyone in the society.

Recognizing that scarcity rules our lives and that we all are constrained by time and money, free enterprise businesses and firms (whether they are small, medium-sized or large) as well as managers (employed or self-employed) are the actors that have to make the choices which ultimately guarantee economic survival. As 'there is no such thing as a free lunch', when making choices then one faces tradeoffs which means that one incurs an opportunity cost that arises from foregoing the next best alternative course of action (which is the activity not chosen). Those actors with the lowest opportunity costs will come out as the winner in the competitive race for economic profits that takes place in highly competitive markets. Making better choices than your competitors requires a better strategy that then (hopefully) results in a sustainable competitive advantage over the rivals. But what is a good strategy? [2,3]. On the one hand, strategy has to do with making good economic choices of what to produce. You have to produce and offer something unique, a good or service that is valuable in the eyes of the consumer (who then would be willing to spend his/her hard-earned money for your good or service). On the other hand, you have to decide about the way how to produce. Being under the constant pressure to improve productivity, this requires cost efficiency, that is, you have to produce the good or service at lowest cost in order to make the profit as high as possible.

This is where the "Jugaad mind set" comes into play! Jugaad (a word taken from Hindi which captures the meaning of finding a lowcost solution to any problem in an intelligent way) is a new way to think constructively different about innovation and strategy. It has a long-lasting tradition in India but is also widely spread in the rest of the BRIC countries and numerous other emerging economies. Jugaad is about extending our ("Western") understanding of entrepreneurial spirit (in the traditional Schumpeterian style). Jugaad means thinking in a frugal way and being flexible, which, in turn, requires to adapt quickly to (often unforeseen) situations and uncertain circumstances in an intelligent way; intelligence in this context "isn't about seeking sophistication or perfection by over-engineering products, but rather about developing a 'good-enough' solution that gets the job done" [4]. This very pragmatic approach is definitely different from the extreme pressure that highly sophisticated production processes impose on managers who are faced with the expectation to deliver dramatic operational improvements all the time. In order to overcome this problem, Jugaad names the following six guiding principles [4]: Seek opportunity in diversity; do more with less; think and act flexibly; keep it simple; include the margin; follow your heart. As these principles carry some universal truth they can be applied in any (developed or emerging) competitive environment!

The best known practical example of Jugaad Innovation in Asia is certainly Tata Motors. It is India's largest car manufacturer who (since March 2009) is able to offer the standard version of the 'Nano Model' for less than US $\$ 2.100$ [5].

\section{Outlook}

What can the JBFA as one of the leading Open Access Journals contribute to spread out the idea of Jugaad Innovation?

Being part of an open access platform provided by OMICS Publishing Group we are trying to open up new avenues for an exchange of ideas among researchers, entrepreneurs and practitioners of Jugaad innovation. This can be done through either publications (for example, by delivering academic research papers to be published in a special "Jugaad Edition" of the JBFA) or the organization of a Jugaad-related scientific conference (using OMCS's conference platform). Thus, we, as Editors - can help to build up a fruitful academic environment by joining forces, creating synergies by bringing together actors from different scientific disciplines and applied fields of interest related to the idea of Jugaad Innovation.

\section{References}

1. Schumpeter JA (1942) Capitalism, Socialism, and Democracy. (3rdedn), Harper and Brothers, New York, USA.

2. Montgomery CA (2012) The Strategist: Be the Leader Your Business Needs. Harper Business, New York, USA

3. Porter ME (1996) What is Strategy? Harvard Business Review.

4. Radjou N, Prabhu J, Ahuja S (2012) Jugaad Innovation: Think Frugal, Be Flexible, Generate Breakthrough Growth. Jossey-Bass, San Francisco, USA.

5. http://www.economist.com/node/13754045.

*Corresponding author: Ingo Bobel, Department of Economics, International University of Monaco, MC-98000 Monte Carlo, Monaco, Tel: 377-97-986-986; Fax: 377-92-052-830; E-mail: ibobel@monaco.edu

Received July 24, 2012; Accepted July 27, 2012; Published August 01, 2012

Citation: Bobel I (2012) Jugaad: A New Innovation Mindset. J Bus \& Fin Aff 1:e116. doi:10.4172/2167-0234.1000e116

Copyright: (c) 2012 Bobel I. This is an open-access article distributed under the terms of the Creative Commons Attribution License, which permits unrestricted use, distribution, and reproduction in any medium, provided the original author and source are credited. 